\title{
Social media as a tool for developing learning spaces of city universities around the world
}

\author{
Elena Petryaeva ${ }^{1 *}$, Daria Milyaeva ${ }^{2}$, Deirdre Wynter $^{3}$, and Natalia Ageeva ${ }^{2}$ \\ ${ }^{1}$ Moscow City University, Institute of System Projects, Moscow, Russia \\ ${ }^{2}$ Moscow City University, International Relations Department, Moscow, Russia \\ ${ }^{3}$ Dublin City University, Marketing Department, Dublin, Ireland
}

\begin{abstract}
In the context of the digital transformation of education, this study focuses on the analysis of social media as an efficient tool for developing learning spaces of universities. The goal of this study is to explore the use of Instagram by city universities, highlight the existing trends, and determine best practices and high-potential directions of online development for universities. The evidence base of this study included the Instagram accounts of six city universities of the world, specifically: the Moscow City University, the Dublin City University, the University of Taipei, the City, University of London, the City University of New York, and the City University of Hong Kong. The research was conducted using the method of content analysis with the use of Google Data Studio services. The analysis uncovered the following topic-based groups of content featured in the Instagram accounts of city universities: Personalities, University, Applicants, Learning and career, Science and technologies, City, Society and politics, Art, and Atmosphere. Subsequently, four high-potential directions of online development were identified for universities: first, more active user engagement and support; second, development of new forms of teaching and learning activities; third, popularisation of research; fourth, branding the university as a partner of the city. The novel contribution of this paper consists in engaging modern analytical tools to visualize a university profile from its published online content. The findings can be used by universities as recommendations on developing and adjusting their content strategies to adapt to the ever-changing realities and ensure effective online promotion and realization of their teaching potential.
\end{abstract}

Keywords: city university, Instagram, digital identity.

\section{Introduction}

Digital transformation has become a prevalent trend in all areas of life in the modern society. National governments initiate projects to promote the digital economy [1-3]. In a fast and abruptly changing reality shaped in particular by the COVID-19 pandemic, the features of the new post-industrial society, such as social media and the online personality, have increasingly become visible.

\footnotetext{
* Corresponding author: petryaevaeyu@mgpu.ru
} 
Social media have driven content development and sharing between different communities and maintained control over the main trend of the social culture of the digital society [4]. Social media serve as the platform for conducting business, expert branding, and facilitating education [5]. Society is actively exploring the potential of the web and selftraining by means of online courses, marathons, and useful content [6]. The intensive growth of data has given rise to a new science research paradigm, Data-Intensive Science, which prioritizes collaboration of scientists, cloud computing, and visualization [7]. For universities, social media create the space to build and promote their digital identity [8]. These and other trends invite thoughts on the online future of universities.

This paper constitutes an attempt to consider the current experience of city universities with social media and to represent best practices and high-potential ways to use them.

\section{Methods}

Six city universities from the world's major cities were selected for analysis, specifically: the Moscow City University (MCU), the Dublin City University (DCU), the University of Taipei (UT), the City, University of London (CUL), the City University of New York (CUNY), and the City University of Hong Kong (CityU). The main reason behind this selection is that the mission of city universities shows the strongest social focus in that it includes working out education programs to suit the city's needs and developing the city's public learning spaces and urban environment [9]. Moreover, the affiliation with city administration enables universities to adopt innovative approaches and technologies in all their activities. The selected sample also provides for geographic diversity as it extends from Europe to America to Asia.

The choice made in this study is to focus on Instagram since its online space spans the biggest user community. Based on the data for 2019-2020 [10], Instagram counts more than 1 billion users globally (116 million in the USA, 42 million in Russia, 22.9 million in the UK), while 500 million of them are active users checking in daily. Instagram shows the highest engagement rate (ER) for the topic of education at $3.57 \%$ (vs. $0.15 \%$ on Facebook, $0.091 \%$ on Twitter) [11].

Taking guidance in the current research on higher education trends [12] and the role of social media in university promotion $[13,14]$, we focused our analysis on the following aspects:

1) user numbers and publications

2) universities' objectives in using social media

3) target audience profiles

4) language used in publications

5) topic-based content categories.

Adapting the input from the paper by N. S. Ageeva [15], we identified eight topic-based groups of content: Personalities, University, Applicants, Learning and career, Science and technologies, City, Society and politics, and Art. One additional group of content was also included, reflecting emotional reactions and student engagement in the university's online activities. We dubbed this group "Atmosphere".

The research was conducted using the method of content analysis with the use of Google Data Studio services.

\section{Results}

The findings concerning university profiles, account statistics, objectives, target audiences, languages used in publications, and topic-based groups of content are laid out in Figure 1. 


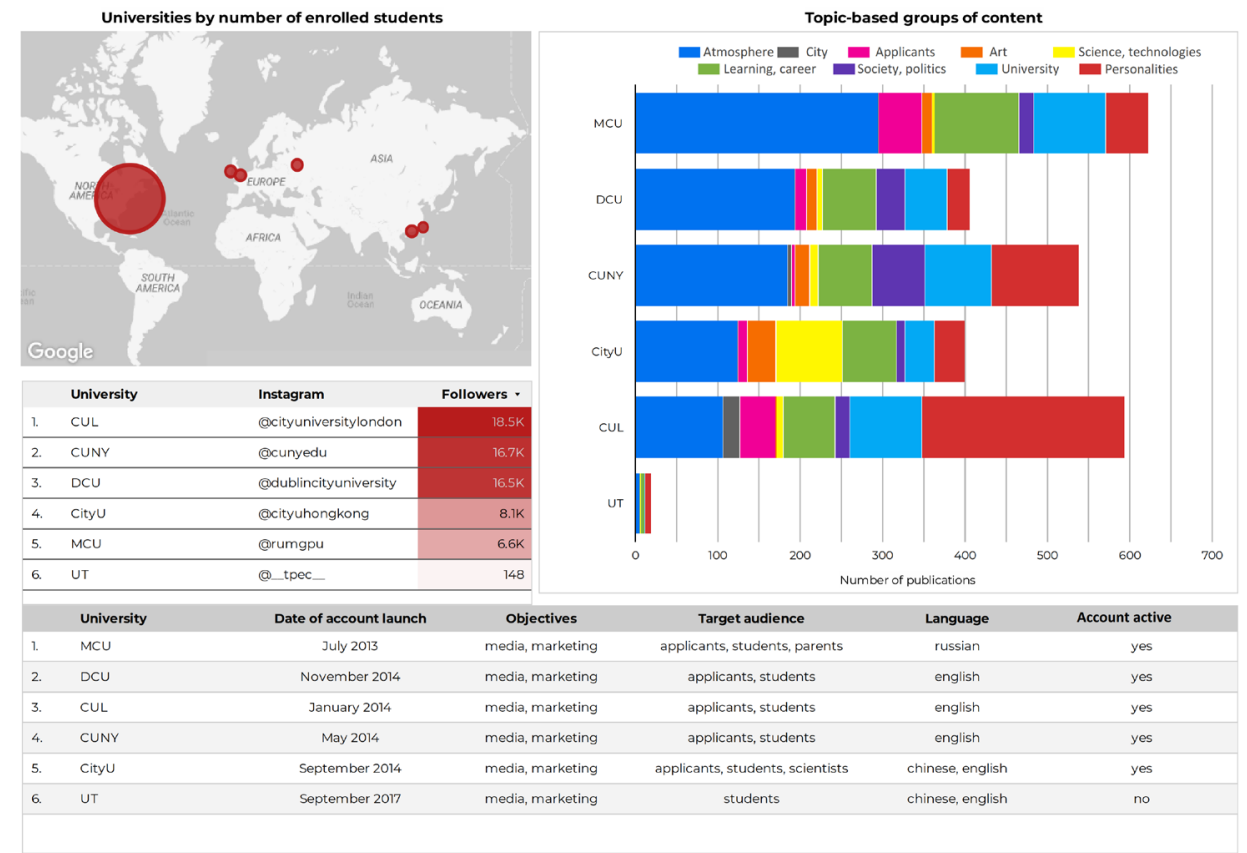

Fig. 1. Profiles of official Instagram accounts of city universities.

Figure 2 presents a comparison of the number of publications in the universities' official Instagram accounts by subtopics in the most popular topic-based groups of content.

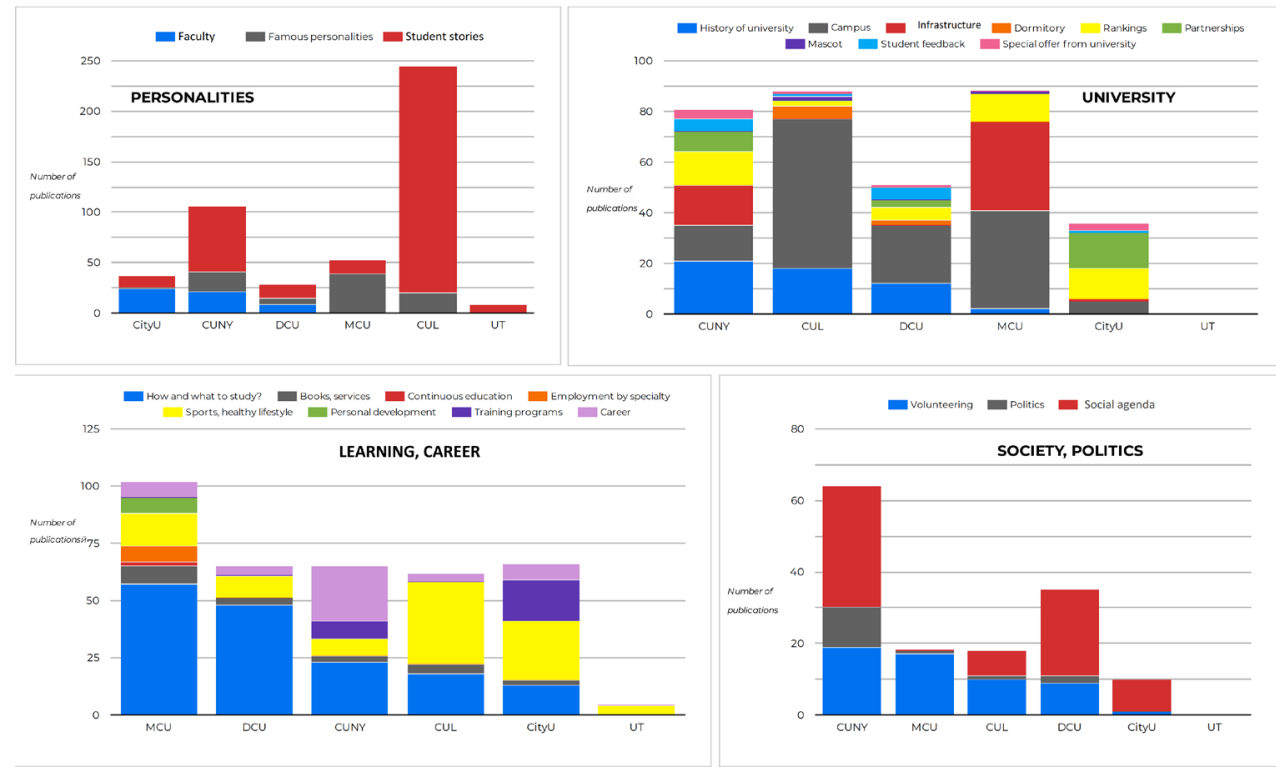

Fig. 2. Popular topic-based groups of content in the universities' official Instagram accounts.

Figure 3 represents the number of publications on subtopics in the topic-based group Atmosphere. 


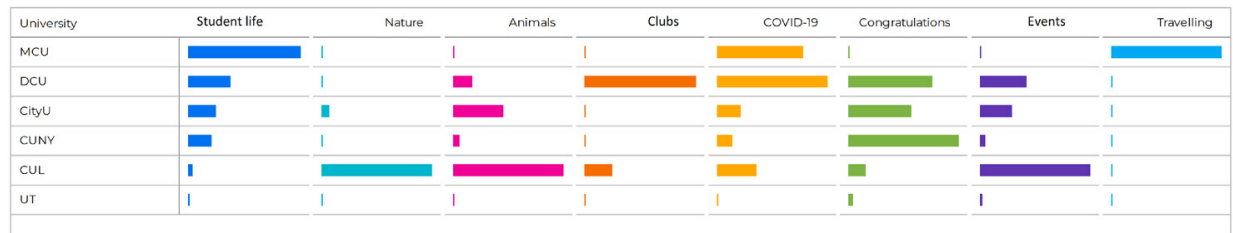

Fig. 3. Publications in the topic-based group Atmosphere.

\section{Discussion}

Let us consider the comparative profiles of the official Instagram accounts of city universities according to the selected parameters.

The accounts of the DCU, the CUL, and the CUNY have the biggest follower audiences, counting more than 16 thousand people each. The Instagram account of the CityU is followed by 8.1 thousand users, while the MCU counts 6.6 thousand followers. The Instagram page of the UT is followed by 143 people due to its decision in 2018 to divert resources toward positioning in social media such as LINE, WeChat, and WhatsApp.

Active Instagram users are the MCU (more than 600 publications), the CUL (593 publications), and the CUNY (538 publications). Most of what is published as the universities' social media content (more than 30\%) falls into the topic-based group Atmosphere. The exception is the CUL, with only $17.9 \%$ of its total Instagram content focusing on this topic. The notable subtopics in this group include:

- MCU: Student life, COVID-19, Travelling,

- DCU: Clubs, COVID-19, Congratulations,

- CUL: Nature, Animals, Events,

- CUNY: Congratulations,

- CityU: Animals, Congratulations (Fig. 3).

The dominant topic-based group for the UT is Personalities representing more than $42 \%$ of the content published in the account. Personalities is the second biggest topic in the accounts of the CUL (more than $40 \%$ of content) and the CUNY (19.7\% of content). This topic-based group represents less than $10 \%$ of the content for other universities. Notably, the CUL's and the CUNY's publications on this topic mostly feature Student stories, while Famous personalities and Faculty are the focus in the MCU's and the CityU's cases respectively (Fig. 2).

Quite prominent is the topic-based group Learning and career. On average, more than $15 \%$ of the content in the universities' accounts relates to publications on How and what to study; Books, services; Employment by specialty; Personal development; Sports and healthy lifestyle; Continuous education; Career; Training programs.

Popular in this group for all universities (except the UT) is the subtopic of How and what to study. The MCU and the DCU are ahead with this thematic content. The subtopic of Sports and healthy lifestyle is visibly present in the accounts of the CUL, the CityU, and the UT. The CUNY and the CityU emphasize the subtopic Training programs. It is mostly missing in the accounts of other universities. The CUNY runs more publications on the problem of Career compared to all other universities. The MCU's specific focal points in this group are the subtopics Personal development, Employment by specialty, and Continuous education.

On average, more than $11 \%$ of the content in the official Instagram accounts of the universities falls into the topic-based group University. The CUL (15\%), the CUNY (15\%), 
and the MCU (14\%) have the biggest share of publications about themselves. The topic is not addressed in the UT's account. Notable subtopics in this group include:

- MCU: Campus; Infrastructure.

- DCU: Campus; History of the university.

- CUL: Campus; History of the university.

- CUNY: History of the university; Campus; Infrastructure; Rankings.

- CityU: Partnerships; Rankings (Fig. 3).

The topic-based group Society and politics is also popular. Here, the CUNY is ahead by the number of publications. The biggest subtopic is Social agenda including environmental issues, LGBT support, women's rights protection, and racial discrimination issues. Posts under this topic are also visibly present in the DCU and the CityU. The dominant subtopic of the MCU and the CUL in this topic-based group is Volunteering. This topic-based group is not addressed in the UT's account. The analysis of this content group suggests that universities actively use social media to influence attitudes in certain areas and show potential ways to solve problems.

The topic-based groups Applicants, Science and technologies, Art, and City do not generally constitute a dominant concern, however they provide some insight into the specifics of their social media content. E.g., 7\% and 8\% of the MCU's and the CUL's content respectively are publications for Applicants. The CityU is ahead by publications on Science and technologies developed at the university. This topic represents $20 \%$ of the content in the Instagram account. For other universities, the share of content concerning Science and technologies is $1-2 \%$. The CityU's another big focus is $\operatorname{Art}$ ( $8.5 \%$ of content). Where it comes to the topic City, the CUL is the only university running publications directly addressing city initiatives (more than $3 \%$ of content).

\section{Conclusion}

The analysis of the official Instagram accounts of city universities helped to establish several high-potential directions of efficient development of the learning spaces of the universities.

The first direction is a more active user engagement and support. The specific ways may include different forms of communication: surveys, votes, comments, private messaging, blocks of reviews, and Q\&As.

For example, the DCU has transformed its Instagram account from an entertainmentoriented one into a student news hub being the primary source of awareness and university news for its students.

Given that the digital identity of a university is built not only within its official account, an important element of promotion is engaging the accounts of other university divisions, informal accounts of students, faculty members, researchers, and partner organizations.

The second high-potential direction is the implementation of new forms of teaching and learning activities in social media. A crucial element is streaming lectures and launching engaging educational events and discussions open to both students and external participants.

One useful online practice is the opportunity of immersing into the life of students and alumni. For example, the DCU initiated the "Day in the life" feature in which alumni conduct online streams from their workplaces (like the Google company) to help current and prospective students visualize their possible future employment.

What makes this direction relevant is that social media is a platform where a broad audience of users can get a glimpse of the university agenda, try various educational formats, contemplate on the future career potential, and eventually decide whether or not to enter the university.

The third direction of using social media is the popularisation of research conducted by the university both among its peers and outside the scientific community. Social media is a 
tool to drive attendance at scientific events and attract the wider community to take part in important discussions. The conducted analysis indicates that for now, the City $\mathrm{U}$ is ahead in utilizing the potential of Instagram for advancing its scientific activities.

The fourth direction is branding the university as a partner of the city. Among the analyzed city universities, only the CUL is to some extent revealing the specific profile in its publications. The goal is to create more content to drive the engagement of city populations in the university's research activities and integration of students in the city life.

Social media of universities is an interface to shape relations between society and education. Competent arrangement of the online learning space can facilitate communications between the university and its target audiences as well as boost its educational potential.

\section{References}

1. European Commission, Digital Education Action Plan (2021-2027) (European Commission, Luxemburg, 2020). Accessed on: December 16, 2020. [Online]. Available: https://ec.europa.eu/education/education-in-the-eu/digital-education-actionplan_en

2. Decree of the President of the RF O natsional'nykh tselyakh i strategicheskikh zadachakh razvitiya Rossiyskoy Federatsii na period do 2024 goda [On National and Strategic Development Objectives of the Russian Federation to 2024] No. 204 dated 07 May 2018 (2018). Accessed on: December 16, 2020. [Online]. Available: http://publication.pravo.gov.ru/Document/View/0001201805070038

3. Tsifrovaya transformatsiya $\mathrm{v}$ Rossii - 2020. Obzor i retsepty uspekha [Digital transformation in Russia - 2020. Outlook and success factors]. Analytical report based on a survey of Russian companies (2020). Accessed on: December 16, 2020. [Online]. Available: https://komanda-a.pro/projects/dtr_2020

4. I. Levin, Cultural trends in a digital society, in Proceedings of TMCE 2014, 19-23 May 2014, Budapest, Hungary (2014). Accessed on: December 16, 2020. [Online]. Available: https://www.tau.ac.il/ ilia1/publications/100-levin-2014.pdf

5. L. Eger, D. Egerová, K. Miroslav, Romanian Journal of Communication and Public Relations, 21(1(46)), 7-30 (2019). https://doi.org/10.21018/rjcpr.2019.1.268

6. S. Wheeler, Future Internet, 1(1), 3-13 (2009). https://doi.org/10.3390/fi1010003

7. I. Levin, International Journal of Design Sciences and Technology, 22(1), 67-80 (2016)

8. A.V. Shchepilova, O.A. Suleimanova, M.A. Fomina, A.A. Vodianitskaya, Vestnik MGPU. Seriya: Filologiya. Teoriya yazyka. Yazykovoe obrazovanie, 3(27), 68-82 (2017). Accessed on: December 16, 2020. [Online]. Available: https://resources.mgpu.ru/docfulldescription.php?docid=454541

9. W. van Winden, City \& University: A symphony for progress (URBACT European Programme for Sustainable Urban Development, Amsterdam, 2015)

10. T. Tran, Instagram Demographics That Matter to Social Media Marketers in 2020. Hootsuite (February 4, 2020) Accessed on: December 16, 2020. [Online]. Available: https://blog.hootsuite.com/instagram-demographics/

11. B. Feehah, 2020 Social Media Industry Benchmark Report (Rival IQ, Seattle, 2020). Accessed on: December 16, 2020. [Online]. Available: https://www.rivaliq.com/blog/social-media-industry-benchmark-report/

12. Pearson, The Global Learner Survey (Pearson, London, 2020). Accessed on: December 
16, 2020. [Online]. Available: https://www.pearson.com/content/dam/one-dotcom/one-dot-com/global/Files/news/gls/Pearson_Global-LearnersSurvey_2020_FINAL.pdf

13. I.N. Timofeev, E.O. Karpinskaia, D.O. Iarkova, M.A. Frantsuzova, I.A. Bocharov, Elektronnaya internatsionalizatsiya: angloyazychnye internet-resursy rossiiskikh universitetov (2020) [Web Internationalization: online English-language resources of Russian universities (2020)], Report No. 57/2020 (Russian International Affairs Council, Moscow, 2020). Accessed on: December 16, 2020. [Online]. Available: https://russiancouncil.ru/activity/publications/elektronnaya-internatsionalizatsiyaangloyazychnye-internet-resursy-rossiyskikh-universitetov-2020-g/

14. A.A. Skliarenko, Obrazovatelnye tekhnologii i obshchestvo [Educational Technology and Society], 22(2), 24-31 (2019)

15. N.S. Ageeva, Setevoi storitelling kak strategiya formirovaniya imidzhevogo portreta universiteta [Online storytelling as a strategy for developing the style profile of a university], in Collection of papers of Master and $\mathrm{PhD}$ program students (Yazyki Narodov Mira, Moscow, 2020) 